\title{
BEACONDRIOD: AN AUTOMATED STUDENT ATTENDANCE SYSTEM
}

\author{
AREE ALI ${ }^{1}$ and BAMO NADIR \\ ${ }^{1}$ College of Engineering, Komar University of Science and Technology-Iraq
}

(Accepted for Publication: December 8, 2020)

\begin{abstract}
Until today, student attendance taking proves to have remained as one of the most challenging tasks in educational organizations. Time efficiency, authenticity together with cost have been major influential factors for many proposed systems in the past to tackle such a challenging task. Nevertheless, such proposed systems lack one or more of these issues. This paper introduces an idea in which smartphones owned by students and teachers are used as the main building blocks of an attendance system that addresses these three major issues. The proposed system takes advantage of the built-in Bluetooth Low Energy (known as BLE) of the smartphones such that it turns them into Beacon Transmitters and Receivers. Two different applications are developed, one of which is installed on the student smartphones turning into a Beacon Transmitter while the other is installed on the instructor's device acting as a Beacon scanner. Students are automatically marked as present, once s/he enters the classroom with the app running. When the instructor is satisfied with the attendance, s/he can send the data to a remote server.
\end{abstract}

KEYWORDS: Beacon; Attendance System; iOS; Android; IoT.

\section{INTRODUCTION}

$\mathbf{G}^{-}$ enerally speaking, student's attendance is mandatory in many institutes and universities. It even requires a certain attendance rate in class in order to pass the course. It takes a considerable amount of time/effort to record when the process is paper-based and/or the number of students is high and it is prone to error. This gives us no choice but to have them recorded in the best way possible with less human involvement or/and time-consumption, and with high accuracy. Although it is still arguable that recording student's attendance to be one of the requirements, the study shows student attendance will affect students' lives even after graduation in their place of work, and absenteeism will have an impact on their grades and knowledge for the class (Credé, Roch and Kieszczynka, 2010).

aree.ali@komar.edu.iq;
Several researches take the advantages of smartphones for taking attendance due to the fact that smartphones now have become the necessity of people's life (Bhih, Johnson and Randles, 2016). All in all, those systems that have been developed for the purpose of recording attendance can fall into three categories based on what they are focusing on (A: Accuracy, B: Speed, C: Cost) or a bit of mixed among them. In this study, we propose the implementation of a smart fully automated beacon-based system in a/an (accurate, speedy, costless) way to be used for taking students' attendance by instructors.

Bluetooth Low Energy (BLE) is a Personal Wireless Area Network (PWAN) like classical Bluetooth. The main difference is the former has significantly lower power consumption and costs less. The lower power consumption of BLE has made it popular in apps of Internet of Things and Beacon technology. Beacons are small hardware bamo.nadir@komar.edu.iq ${ }^{1}$ Corresponding author: College of Engineering, Komar University of Science and Technology, Kurdistan Region, Iraq 
devices based on BLE technology broadcasting (peripheral) / listening (receiver) for radio signals.

iBeacon from Apple and Eddystone from Google are the two main standard protocols based on which many companies have manufactured beacon devices. Both Android and iOS support acting as either Peripheral or Receiver allowing the proposed system to use the instructor's smartphone as receiver and student's mobile device as the peripheral (Android Beacon Library, no date; Turning an iOS Device into an iBeacon Device | Apple Developer Documentation, no date). The proposed system uses the open-source Altbeacon Android Liberary on both of the applications turning one to a beacon scanner while the other no date).

After the instructor enters the classroom and opens the app installed on his/her device, $\mathrm{s} / \mathrm{he}$ is presented with a list of classes s/he is teaching, from which s/he can select the one to take attendance for. Students need to switch on their device's Bluetooth to be found by the instructor's app in the minimum amount of time.

In order to aid the readers, this paper is written as follows: Section II, which highlights the related works, followed by section III discusses the proposed system and working. Subsequently, section IV shows the requirement of the system with some of its subsections, section $\mathrm{V}$ which explains the implementation of the system and finally the conclusion.

\section{RELATED WORKS}

An equitable number of researchers has conducted in this area, all of them were to facilitate the process of taking student attendances and improve it in (performance, accuracy or cost) or sometimes in all of them. There are several approaches/techniques to solve to a beacon transmitter (Android Beacon Library,

this problem, such as using an RFID-based system, Bluetooth-based system, facial recognition, and Beacon ${ }^{\circledR}$ to transmit/send data.

Recording student attendance is not a new issue, in fact, it has been around for many great years that has led to many researches being published to tackle it. A semi-automatic attendance system is explained that works on facial recognition, the downside of such an approach is the need of extra high-quality equipment and computational power leading to extra cost "Facial Recognition system needs a large image to be used for face detection" (Chintalapati and Raghunadh, 2013). The cost is eliminated in a proposed system that uses the personal mobile phone camera to take a photo of the students in the class and send it to a server for face detection and recognition process, this solution is great in terms of budget as it does not require any extra devices, however, it is argued that pose variation, lighting conditions or facial expression impact the result let alone the time that needs to prepare the list of present/absent students. The downside of this system is cost and time to configure it and also not that much speed during its use (Samet and Tanriverdi, 2017; Akbar et al., 2019).

A different type of semi-automated system was proposed that uses RFID/QR technique, the pros of such an approach are creating queue at the entrance of the classroom or at any place where the RFID reader is installed, time-consuming, the possibility for students to carry their friends' card without being in the class physically (Verma and Gupta, 2013; Chennattu et al., 2019). Fingerprint technology is another technique to be used for taking attendance, but overall, those biometrics systems are costly and again students' queue may occur (Badejo et al., 2018; Koppikar et al., 2019).

Another approach that seems to be more popular for taking attendance is using Beacon. In such approaches, a Beacon device is installed in bamo.nadir@komar.edu.iq ${ }^{1}$ Corresponding author: College of Engineering, Komar University of Science and Technology, Kurdistan Region, Iraq 
the classroom and students require to install a provided app that scans for beacon's signal. Once the beacon is detected, the app sends the students details together with the beacon ID to a server to mark students as present. The cost of buying a beacon for each class is a major downside of this approach which is common with other approaches (Noguchi et al., 2015; Apoorv and Mathur, 2017; Azmi et al., 2019).

Overall, the systems that have been introduced and implemented are somehow costly, time-consuming, and also takes more time to record the attendance with. There is also another point that we need to take it into consideration, which is accuracy. The data that is recorded may not be $100 \%$ accurate and that causes problems.

\section{PROPOSED MODEL}

One of the distinguishing advantages of the proposed model is the fact that the need of buying a beacon device for every lecture room is eliminated resulting in reducing cost to zero. In previous researches beacon devices were the central point of the proposed systems requiring a considerable amount of money to be spent on buying such devices let alone the time required to configure and install them.

In our approach, the instructor's smartphone acts as a beacon receiver (beacon central) that receives data from students' (attendees') smartphones (peripheral). To take attendance, an instructor just needs to launch the app so it starts scanning for nearby beacon transmitters (the students' smartphones) and automatically marks them as present/absent. The instructor saves the result of the scanning once $\mathrm{s} / \mathrm{he}$ is satisfied with the results which are sent to the cloud to be stored permanently.

The app itself requires no configuration by instructors during its usage as all the data such as student and course information, lecture hall and date/time that the instructor is teaching (currently) will be driven from a server. Both apps integrate with the already available Class Management Information System REST API to receive the necessary data.

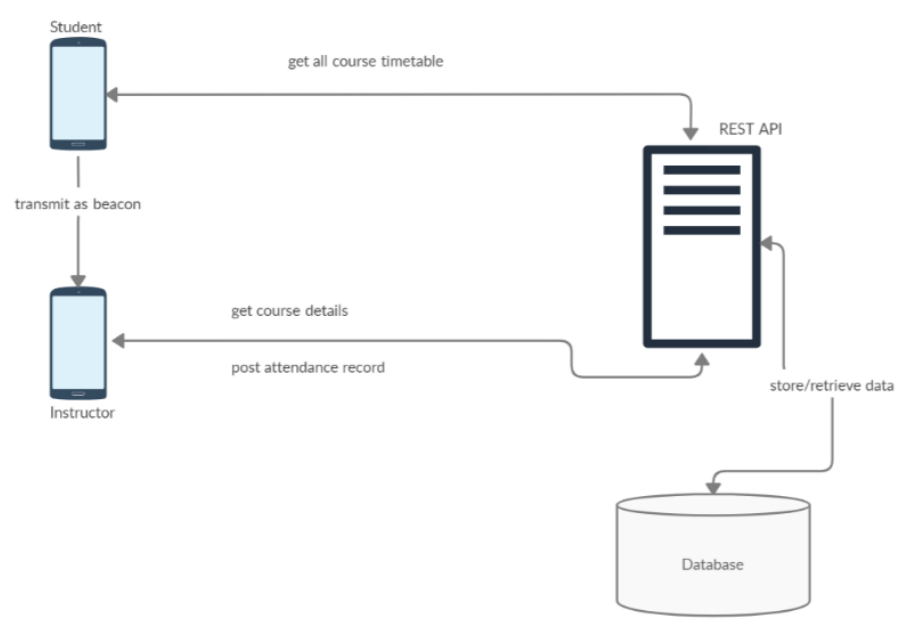

Fig. (1): Flowchart of the system (System Diagram)

\section{IMPLEMENTATION}

The proposed system consists of two mobile apps and a REST API, in which ONLY the instructor's device needs to be connected to the internet, as shown in figure 1 (Overview of the system). One is installed on students' mobile devices which returns them into a beacon bamo.nadir@komar.edu.iq 
transmitter leveraging the BLE peripheral mode supported by both Android and iOS latest releases.

The app uses the student ID as its beacon minor ID and is setup in a way that it transmits the beacon signal in the background only when the time is within the students' class schedule. It uses Android AlarmManager to compare the current time with the list of the class timetables that are retrieved and cached locally the first-time app runs. The first time the student opens the app, it will ask for username and password. After successful authentication, the student is redirected to the home screen in which a list of classes $\mathrm{s} / \mathrm{he}$ is registered for is displayed. In this screen, the student can view the attendance rate for each of the courses $s /$ he is registered for.

The other app is installed on the instructor's mobile device that scans for beacon signals. When a valid beacon ID is found, it will be marked as present. Once satisfied, the instructor can save the result by sending it to the REST API. The instructor needs to open the app during every class from which s/he can select the class for which attendance needs to be taken. The app

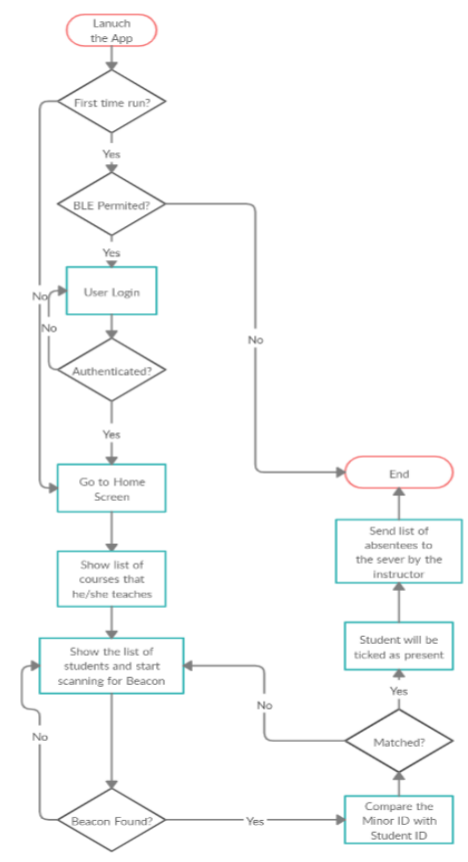

Fig. (2): Flowchart of Instructor's App then starts scanning for beacons comparing the beacon's minor ID with the ID of each registered student in the class. Once a match is detected, the student is marked as present. The app allows manually marking a student as present, absent or late in the event that the beacons scanner is unable to detect an actually present beacon.

Both mobile apps authenticate the user by sending the user credentials to a REST endpoint the response of which is a JSON Web Token (JWT) that is cached in the mobile device and added to the header of every request made to the REST API then after. In this way, the users of the apps do not need to login to the system on every app launch. This is particularly important for the instructor as s/he needs to be connected to the REST API in order to be able to save the attendance.

Figure 2 shows the diagram of the instructor's app in which s/he needs login to the app inside the classroom and search for the students' BLE as we extensively mentioned before. As for figure 3 shows the system diagram of students' app, their mobile's Bluetooth has to be switched on in order to be found by the instructor's mobile derive.

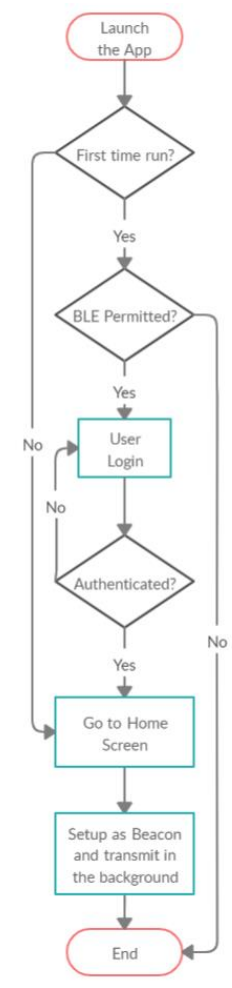

Fig. (3): Flowchart of Student's App

aree.ali@komar.edu.iq; bamo.nadir@komar.edu.iq ${ }^{1}$ Corresponding author: College of Engineering, Komar University of Science and Technology, Kurdistan Region, Iraq 
Figure 4 and 5 show the app installed on the instructor's device. Figure 4 shows that the instructor has the option to change the range of scanning (iBeacon tutorial - Part 3: Ranging

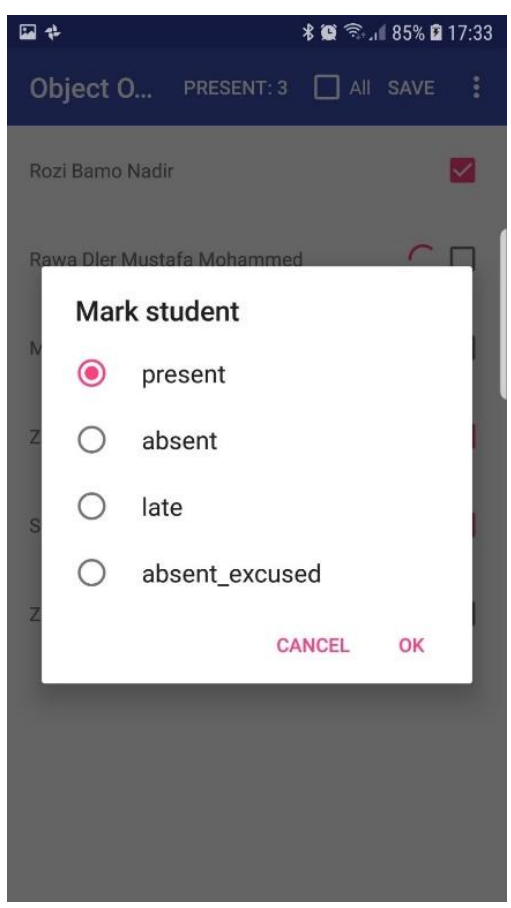

Fig. (4): Scanning Range

\section{CONCLUSION}

In this paper, we have discussed an automated system to record the student attendance during lectures without using any extra device. The idea is to make students' smartphones to work as Beacons and to transmit data that can be done without even having an internet access.

Upside of this system is, since it works with students' smartphones and it is not very likely students give out their smartphones to others just in order to be marked a present without being in the class physically, and there is no need of buying any extra equipment. The proposed system requires both students and the instructor to turn on the Bluetooth on their mobile phones beacons - Estimote Developer, no date). As figure 5 illustrates, the instructor can also manually take the attendance in the event of a beacon not being detected

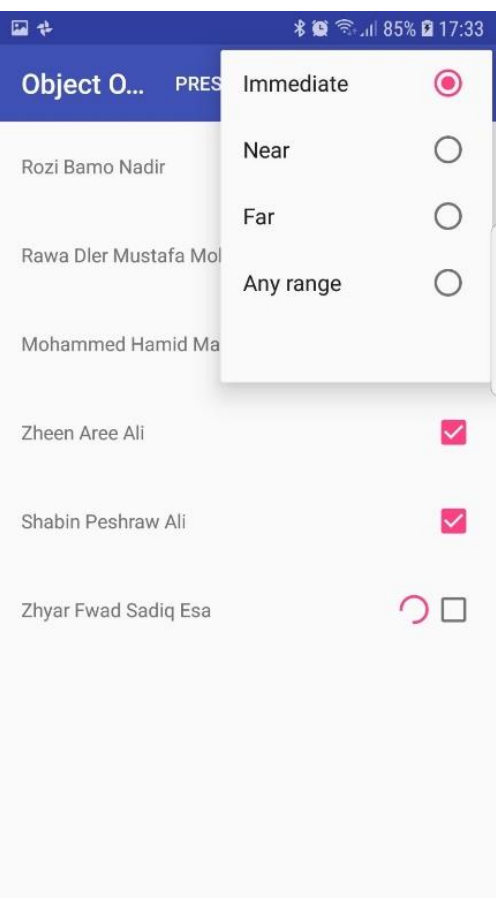

Fig. (5): Marking Student View

when taking attendance which could be regarded a disadvantage of the system as having Bluetooth on adds extra power consumption.

\section{REFERENCES}

Akbar, M. S. et al. (2019) 'Face Recognition and RFID Verified Attendance System', Proceedings - 2018 International Conference on Computing, Electronics and Communications Engineering, iCCECE 2018. IEEE, pp. 168-172. doi: 10.1109/iCCECOME.2018.8658705.

Android Beacon Library (no date). Available at: https://altbeacon.github.io/android-beacon-libr ary/ (Accessed: 24 June 2020).

Android Beacon Library (no date). Available at: https://altbeacon.github.io/android-beacon-libr bamo.nadir@komar.edu.iq ${ }^{1}$ Corresponding author: College of Engineering, Komar University of Science and Technology, Kurdistan Region, Iraq 
ary/beacon-transmitter.html (Accessed: 24

June 2020).

Apoorv, R. and Mathur, P. (2017) 'Smart attendance management using Bluetooth Low Energy and Android', IEEE Region 10 Annual International Conference, Proceedings/TENCON, pp. 1048-1052. doi: 10.1109/TENCON.2016.7848166.

Azmi, M. S. M. et al. (2019) 'UNITEN Smart Attendance System (UniSas) Using Beacons Sensor', 2018 IEEE Conference on e-Learning, e-Management and e-Services, IC3e 2018. IEEE, pp. 35-39. doi: 10.1109/IC3e.2018.8632631.

Badejo, J. A. et al. (2018) 'Integrating Automated Fingerprint-Based Attendance into a University Portal System', Proceedings - 2017 International Conference on Computational Science and Computational Intelligence,

CSCI 2017. IEEE, pp. 1016-1020. doi: 10.1109/CSCI.2017.175.

Bhih, A. A., Johnson, P. and Randles, M. (2016) 'Diversity in smartphone usage', ACM International Conference Proceeding Series, 1164(June), pp. 81-88. doi: 10.1145/2983468.2983496.

Chennattu, S. et al. (2019) 'Portable Biometric Attendance System Using IOT', 2019 4th International Conference on Information Systems and Computer Networks, ISCON 2019. IEEE, pp. 245-249. doi: 10.1109/ISCON47742.2019.9036275.

Chintalapati, S. and Raghunadh, M. V. (2013) 'Automated attendance management system based on face recognition algorithms', 2013 IEEE International Conference on Computational Intelligence and Computing Research, IEEE ICCIC 2013, pp. 1-5. doi: 10.1109/ICCIC.2013.6724266.

Credé, M., Roch, S. G. and Kieszczynka, U. M. (2010) 'Class attendance in college: A meta-analytic review of the relationship of class attendance with grades and student characteristics', Review of Educational Research, 80(2), pp. 272-295. doi: $10.3102 / 0034654310362998$.

iBeacon tutorial - Part 3: Ranging beacons - Estimote Developer (no date). Available at: https://developer.estimote.com/ibeacon/tutorial /part-3-ranging-beacons/ (Accessed: 24 June 2020).

Koppikar, U. et al. (2019) 'IoT based Smart Attendance Monitoring Systems using RFID', 1st IEEE International Conference on Advances in Information Technology, ICAIT 2019 - Proceedings, pp. 193-197. doi:

\subsection{9/ICAIT47043.2019.8987434.}

Noguchi, S. et al. (2015) 'Student attendance management system with bluetooth low energy beacon and android devices', Proceedings - 2015 18th International Conference on Network-Based Information Systems, NBiS 2015, pp. 710-713. doi: 10.1109/NBiS.2015.109.

Samet, R. and Tanriverdi, M. (2017) 'Face recognition-based mobile automatic classroom attendance management system', Proceedings - 2017 International Conference on Cyberworlds, CW 2017 - in cooperation with: Eurographics Association International Federation for Information Processing ACM SIGGRAPH, 2017- Janua, pp. 253-256. doi: 10.1109/CW.2017.34.

Turning an iOS Device into an iBeacon Device | Apple Developer Documentation (no date). Available

at:https://developer.apple.com/documentation/ corelocation/turning an ios device into an _ i beacon_device (Accessed: 24 June 2020).

Verma, P. and Gupta, N. (2013) 'Fingerprint Based Student Attendance System Using GSM', International Journal of Science and Research (IJSR) ISSN (Online, 2(10), pp. 2319-7064.

aree.ali@komar.edu.iq; bamo.nadir@komar.edu.iq ${ }^{1}$ Corresponding author: College of Engineering, Komar University of Science and Technology, Kurdistan Region, Iraq 